\title{
Assessment of dysglycemia risk in the Kitikmeot region of Nunavut: using the CANRISK tool
}

\author{
Ying Jiang, MD (1); Susan Rogers Van Katwyk, BSc (1,2); Yang Mao, PhD (1); Heather Orpana, PhD (1,2); \\ Gina Agarwal, MBBS, PhD (3); Margaret de Groh, PhD (1); Monique Skinner, BA (4); Robyn Clarke, BSc (4); \\ Howard Morrison, PhD (1)
}

This article has been peer reviewed.

Tweet this article

\begin{abstract}
Introduction: The Public Health Agency of Canada adapted a Finnish diabetes screening tool (FINDRISC) to create a tool (CANRISK) tailored to Canada's multi-ethnic population. CANRISK was developed using data collected in seven Canadian provinces. In an effort to extend the applicability of CANRISK to northern territorial populations, we completed a study with the mainly Inuit population in the Kitikmeot region of Nunavut.
\end{abstract}

Methods: We obtained CANRISK questionnaires, physical measures and blood samples from participants in five Nunavut communities in Kitikmeot. We used logistic regression to test model fit using the original CANRISK risk factors for dysglycemia (prediabetes and diabetes). Dysglycemia was assessed using fasting plasma glucose (FPG) alone and/or oral glucose tolerance test. We generated participants' CANRISK scores to test the functioning of this tool in the Inuit population.

Results: A total of 303 individuals participated in the study. Half were aged less than 45 years, two-thirds were female and $84 \%$ were Inuit. A total of $18 \%$ had prediabetes, and an additional $4 \%$ had undiagnosed diabetes. The odds of having dysglycemia rose exponentially with age, while the relationship with BMI was U-shaped. Compared with lab test results, using a cut-off point of 32 the CANRISK tool achieved a sensitivity of $61 \%$, a specificity of $66 \%$, a positive predictive value of $34 \%$ and an accuracy rate of $65 \%$.

Conclusion: The CANRISK tool achieved a similar accuracy in detecting dysglycemia in this mainly Inuit population as it did in a multi-ethnic sample of Canadians. We found the CANRISK tool to be adaptable to the Kitikmeot region, and more generally to Nunavut.

Keywords: CANRISK, prediabetes, diabetes, dysglycemia, Nunavut, Inuit

\section{Introduction}

Diabetes (types 1 and 2) and related complications place a heavy burden on Canadians and on the health care system. ${ }^{1}$ Recent Canadian data show that $10 \%$ of adult Canadians aged 20 years and older have been diagnosed with diabetes. ${ }^{2}$ Furthermore, it is estimated that at least one in five individuals with diabetes has not been diagnosed and is unaware that they have the disease. ${ }^{3}$

Risk factors for developing type 2 diabetes include adiposity, age, genetic predisposition, epigenetic factors, being male, unhealthy diet, physical inactivity and other comorbidities such as hypertension. ${ }^{4,5}$ Surrogate genetic measures include family history of diabetes and ethnic origin, with individuals of South Asian ${ }^{6}$ and

\section{Highlights}

- The CANRISK questionnaire is a tool for assessing dysglycemia risk in Canada's multi-ethnic population.

- This study was conducted in a sample from Nunavut; $18 \%$ of study participants had prediabetes and $4 \%$ had undiagnosed diabetes.

- The CANRISK tool achieved similar accuracy in the mainly Inuit population as in a multi-ethnic sample of Canadians.

- The CANRISK tool was found to be adaptable to the Kitikmeot region, and more generally to Nunavut.

First Nations ${ }^{3}$ origin at particularly high risk for type 2 diabetes.

In 1987, a comprehensive review of medical charts of Canadian Inuit only identified 31 prevalent cases of diabetes in adults aged 25 years or over, resulting in an age-standardized prevalence of $0.6 \%$. $^{7}$ The International Polar Year Inuit Health Survey for Adults 2007-2008 noted a diabetes prevalence of $5.1 \%$ based on the oral glucose tolerance test (OGTT), which was comparable to that of the general Canadian population. ${ }^{8}$ However, the same survey observed high rates of obesity among the Inuit ${ }^{8}$ compared to the general Canadian population. ${ }^{9}$ The importance of obesity in the etiology of type 2 diabetes suggests that type 2 diabetes rates are likely to increase in the near future in this population.

\section{Author references:}

1. Public Health Agency of Canada, Ottawa, Ontario, Canada

2. University of Ottawa, Ottawa, Ontario, Canada

3. Department of Family Medicine, McMaster University, Hamilton, Ontario, Canada

4. Kitikmeot Region Health and Social Services, Cambridge Bay, Nunavut, Canada

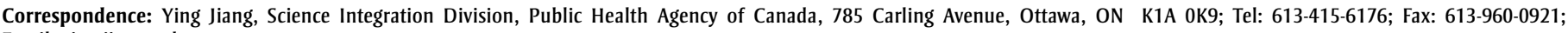
Email: ying.jiang@phac-aspc.gc.ca 
It is important to identify people at risk of developing type 2 diabetes and encourage them to make healthy lifestyle changes to prevent it, or at least postpone its onset, and to identify previously undiagnosed cases of type 2 diabetes so that treatment can begin.

The identification of an individual's diabetes or prediabetes status requires blood tests. If applied to entire populations (e.g. screening once every three years for Canadians aged 40 years and older as recommended by Canadian Diabetes Association 2013 guidelines ${ }^{10}$ ), the result is the screening of many low-risk people. One cost-effective option is to identify highrisk individuals through an initial questionnaire-based screen, and then to conduct further blood testing only on these individuals. Finland used this approach when it developed a questionnaire (FINDRISC) ${ }^{11}$ based on known risk factors for type 2 diabetes. In Canada, the FINDRISC questionnaire was modified based on recommendations from an expert advisory committee to take into account Canada's multi-ethnic composition and other risk factors not captured by the FINDRISC that were considered relevant in the Canadian context. ${ }^{12,13}$ The CANRISK questionnaire was piloted from 2007 to 2011 using a convenience sample of adults mainly aged 40 to 78 years living in seven provinces in conjunction with fasting plasma glucose (FPG) and oral glucose tolerance test (OGTT). ${ }^{12,13}$ These data were used to build and test the CANRISK model using a calibration and validation sample. The predictive ability of the CANRISK model was compared to the FINDRISC model and a model including only body mass index (BMI), waist circumference, sex and age. The model was chosen to maximize the classification of true positives, and assess model fit and statistical significance of individual predictors with a calibration sample. The final model was then crossvalidated on an independent sample. ${ }^{12,14,15}$ Subsequent validations of the use of the CANRISK scoring tool among young adults (aged 20-39 years) in specific ethnic populations are currently underway. CANRISK is being used in a number of jurisdictions in Canada, such as New Brunswick $^{16}$ and the City of Toronto, and by organizations such as Shoppers Drug Mart $^{17}$ and the Canadian Diabetes Association. ${ }^{18}$

Other countries have developed type 2 diabetes risk assessment tools similar to
FINDRISC and CANRISK, such as the Australian Type 2 diabetes risk assessment tool (AUSDRISK), ${ }^{19}$ the UK Diabetes Risk Score Assessment tool ${ }^{20}$ and the US type 2 diabetes risk test. ${ }^{21} \mathrm{~A}$ key difference between these tools is the inclusion of different, country-specific ethnic groups (e.g. Aboriginal and Torres Strait Islander for AUSDRISK) during their developmental stages. Although the current version of CANRISK was developed based on a sample with many ethnicities including First Nations, it currently lacks validation for the Inuit population. The purpose of this study was to examine the fit of the CANRISK model in a mainly Inuit population, and to test the sensitivity and specificity of the current CANRISK tool and cut-off points in identifying dysglycemia (prediabetes and diabetes).

\section{Methods}

The Public Health Agency of Canada (PHAC) conducted a dysglycemia risk score study for the Nunavut population in conjunction with Nunavut Department of Health and Social Services and community public health authorities, following Tri-Council Policy Statement 2 guidelines. ${ }^{22}$ Community engagement occurred through the Kitikmeot Inuit Association. Ethics approval was received from the Health Canada/Public Health Agency of Canada Research Ethics Board and licenced by the Nunavut Research Institute.

\section{Study population and recruitment}

During the period January 2013 to March 2013, we approached residents aged 30 years and over from the five communities in the Kitikmeot region of Nunavut including Cambridge Bay, Gjoa Haven, Kugaaruk, Kugluktuk and Taloyoak to participate in a dysglycemia risk assessment study. We excluded individuals with known diabetes status in order to match the methodology used in the original CANRISK study. Radio announcements, notices on social media such as Facebook and posters in the community were used to advertise the project. All people visiting the community health centres were asked to participate in the project and to spread the word to friends and family members. A $\$ 50$ food voucher was given to participants who completed all the required information (questionnaire and blood tests).

\section{Data collection}

Individuals who provided informed consent were invited to the local public health unit to undergo a personal interview and anthropometric measurements and to give two blood samples. Study participants were weighed dressed in indoor clothing without shoes, using a digital standing scale. Height was determined using a standardized tape measure attached to the wall. Height and weight were measured to the nearest $1 \mathrm{~cm}$ and 100 grams, respectively. Waist circumference was measured as the minimum circumference between the umbilicus and xiphoid process, to the nearest half-centimetre. Community health workers within the communities were able to provide assistance to study participants in English, Inuinnaqtun and Inuktitut, as appropriate, and received standardized training on how to conduct the anthropometric measurements so that the measurements would be standardized across all five study communities.

The CANRISK questionnaire ${ }^{16}$ included questions on sex, age, physical activity, fruit and vegetable consumption, history of high blood pressure, history of high blood glucose, family history of diabetes, ethnicity and education. The average length of time to complete the interview was less than five minutes. In Nunavut, due to interest from the local communities, these interviews were supplemented by dietary questions on the consumption of "junk food" (including sugar-sweetened beverages) and "country foods." "Junk food" encompassed potato chips, crisps, cheese puffs, sugary beverages such as soda, powdered sugar drinks (e.g. fruit drinks/sports drinks, iced tea, hot chocolate) and slush drinks. "Country foods” included muktuk, caribou, Musk ox, birds, animal liver or marine mammal meat such as ringed seal or whale, and fish such as arctic char or white fish.

Participants were requested to provide two blood samples: a fasting venous blood sample, and another venous blood sample two hours after drinking a 75 g glucose drink (constituting the OGTT), as recommended by the World Health Organization and the Canadian Diabetes Association 2013 guidelines. ${ }^{10,23}$ Fasting and OGTT plasma glucose were measured on all blood samples by DynaLIFE ${ }_{D x}$ laboratory in Edmonton.

\section{Data analysis}

We calculated study participation rates by comparing the sample characteristics against 
population data from the 2011 census, by individual community and the sample as a whole.

We analyzed age, BMI $\left(\mathrm{kg} / \mathrm{m}^{2}\right)$ and waist circumference as categorical variables consistent with the categories on the CANRISK questionnaire. ${ }^{13}$ The categories for age in years were 30 to 44,45 to 54 , 55 to 64 and 65 and older. The categories for BMI were less than 25, 25 to 29.9, 30 to 34.9 and 35 and higher. ${ }^{24}$ Waist circumference categories were small (male $<94 \mathrm{~cm}$ and female $<80 \mathrm{~cm}$ ), medium (male 94-102 $\mathrm{cm}$ and female $80-88 \mathrm{~cm}$ ) and large (male > $102 \mathrm{~cm}$ and female $>88 \mathrm{~cm}$ ). ${ }^{25}$

Family diabetes history was measured as a count of the number of categories of firstdegree relatives with diabetes (ranging from 0 to 4). Education included some college or university, high school diploma and less than high school.

Other variables were binary, with yes or no responses to questions such as "Do you usually do some physical activity such as brisk walking for at least 30 minutes each day?"; "Have you ever been told that you have high blood pressure?"; "Have you ever been told that you have high blood sugar?"; and "Have you eaten country food in the past year?" We assessed fruit and vegetable consumption with the question "How often do you eat vegetables or fruits?" with response categories of "Every day" or "Not every day.”

Dysglycemia was determined based on the results of participants' FPG and/or OGTT, with diabetes and prediabetes status defined according to WHO standards. ${ }^{23}$ Individuals were classified as having prediabetes if they had an FPG level of 6.1 to less than $7.0 \mathrm{mmol} / \mathrm{L}$, and/or an OGTT of 7.8 to $11.0 \mathrm{mmol} / \mathrm{L}$. Individuals were classified as having diabetes if they had an FPG level of $7.0 \mathrm{mmol} / \mathrm{L}$ or higher, and/or a 2-hour plasma glucose post-ingestion of $75 \mathrm{~g}$ of glucose of $11.1 \mathrm{mmol} / \mathrm{L}$ or higher.

First, we conducted binary logistic regression, with the CANRISK variables plus the supplementary diet variables, with presence or absence of dysglycemia as the outcome variable. We conducted a second binary logistic regression, forcing only the CANRISK variables in the model. We used the Hosmer-Lemeshow goodness of fit test to assess model fit, and the pseudo-Rsquare statistic to compare these models. We calculated odds ratios (ORs) and 95\% confidence intervals (CIs). We used the area under the receiver operating curve (AUC ROC) to assess the predictive ability of the models. Scores range from 0.5 (no predictive ability) to 1.0 (perfect predictive ability). All analyses were conducted in SAS 9.3 (SAS Institute Inc., Cary, NC, USA).

Second, we ascribed CANRISK scores to participants based on the publicly available CANRISK tool and classified scores as positive or negative with reference to a series of cut-off points: slightly elevated $(\geq 21)$, moderate $(\geq 29)$, balanced $(\geq 32)$ and high risk ( $\geq 33) .{ }^{12}$ A score equal to or above the cut-off point was coded as positive and a score below the cut-off point was coded as negative. Sensitivity is the proportion of those who have a positive CANRISK score among those with a positive FPG and/or OGTT. Specificity is the proportion of those with a negative CANRISK score among those with a negative FPG and negative OGTT. The positive predictive value is the probability that subjects with a positive CANRISK risk score had a positive FPG and/or OGTT. The accuracy rate is the number of positive CANRISK scores confirmed by positive FPG and/or OGTT tests and the number of negative CANRISK scores confirmed by negative FPG and negative OGTT tests out of the total number of participants. We calculated these statistics in this study to determine if the current CANRISK tool and cut-off points could be extended to this Inuit population.

\section{Results}

A total of 303 CANRISK surveys and valid OGTT records were collected from the five selected communities, which covered approximately $11.6 \%(303 / 2614)$ of the local population aged 30 years or older (Table 1). Approximately half of the participants were aged 30 to 45 years, two-thirds were female and $84 \%$ were Inuit.

Table 2 shows the primary risk characteristics of study participants. Of the surveyed population, $67 \%$ were overweight or obese, and $56 \%$ had a high-risk waist circumference of more than $88 \mathrm{~cm}$ for females and more than $102 \mathrm{~cm}$ for males. The mean CANRISK score for this sample $(\mathrm{N}=303)$ was 29.0, $(\mathrm{SD}=12$, median $=28$, minimum $=0$ and maximum $=65$ ).

From laboratory testing, a total of $18 \%$ of the participants in the study were identified as having prediabetes, and $4 \%$ were identified as having diabetes. The proportion of the sample identified as having prediabetes ranged from $12 \%$ to $22 \%$ depending on the community (Table 3 ).

Table 4 provides the results of the logistic regression analyses. Age and macrosomia

TABLE 1

CANRISK Kitikmeot Region (Nunavut) study participation rates by community, Canada, 2013

\begin{tabular}{|c|c|c|c|c|c|}
\hline \multirow[t]{2}{*}{ Community } & \multicolumn{2}{|c|}{ Community population aged 30 and over } & \multicolumn{3}{|c|}{ Participants (n) and community coverage (\%) } \\
\hline & Males & Females & Males & Females & Total \\
\hline Cambridge Bay & 406 & 365 & $33(8.1 \%)$ & $48(13.2 \%)$ & $81(10.5 \%)$ \\
\hline Kugaaruk & 171 & 149 & $11(6.4 \%)$ & $18(12.1 \%)$ & $29(9.1 \%)$ \\
\hline Kugluktuk & 358 & 295 & $22(6.1 \%)$ & $54(18.3 \%)$ & $76(11.6 \%)$ \\
\hline Total & 1393 & 1221 & $104(7.5 \%)$ & $199(16.3 \%)$ & $303(11.6 \%)$ \\
\hline
\end{tabular}

a Population estimates are based on the 2011 census counts adjusted for net census undercoverage.

${ }^{\mathrm{b}}$ Kitikmeot region totals include unorganized areas and outpost camps. 
TABLE 2

Risk characteristics of CANRISK Kitikmeot Region (Nunavut) study participants, Canada, 2013

\begin{tabular}{|c|c|c|c|c|}
\hline & $\begin{array}{l}\text { Males } \\
\% \text { (n) }\end{array}$ & $\begin{array}{c}\text { Females } \\
\% \text { (n) }\end{array}$ & $\begin{array}{l}\text { Total } \\
\% \text { (n) }\end{array}$ & $p$ \\
\hline \multicolumn{5}{|l|}{ Age } \\
\hline$<45$ & $50.0(52)$ & $47.2(94)$ & $48.2(146)$ & \multirow[t]{4}{*}{.15} \\
\hline $45-54$ & $26.0(27)$ & $21.6(43)$ & $23.1(70)$ & \\
\hline $55-64$ & $9.6(10)$ & $19.6(39)$ & $16.2(49)$ & \\
\hline $65+$ & $14.4(15)$ & $11.6(23)$ & $12.5(38)$ & \\
\hline \multicolumn{5}{|l|}{ BMI } \\
\hline$<25$ & $39.4(41)$ & $29.6(59)$ & $33.0(100)$ & \multirow[t]{4}{*}{.05} \\
\hline 25 to $<30$ & $26.9(28)$ & $24.1(48)$ & $25.1(76)$ & \\
\hline 30 to $<35$ & $21.2(22)$ & $20.6(41)$ & $20.8(63)$ & \\
\hline $35+$ & $12.5(13)$ & $25.6(51)$ & $21.1(64)$ & \\
\hline \multicolumn{5}{|l|}{ Waist circumference ${ }^{a}$} \\
\hline Small & $38.8(40)$ & $15.0(29)$ & $23.3(69)$ & \multirow[t]{3}{*}{$<.001$} \\
\hline Medium & $26.2(27)$ & $17.1(33)$ & $20.3(60)$ & \\
\hline Large & $35.0(36)$ & $67.9(131)$ & $56.4(167)$ & \\
\hline \multicolumn{5}{|l|}{ Education } \\
\hline Some college or university & $24.0(25)$ & $23.1(46)$ & $23.4(71)$ & \multirow[t]{3}{*}{.52} \\
\hline High school & $10.6(11)$ & $6.0(12)$ & $7.6(23)$ & \\
\hline Less than high school & $65.4(68)$ & 70.9 (141) & 69.0 (209) & \\
\hline \multicolumn{5}{|c|}{30 Minutes daily physical activity } \\
\hline Yes & $79.8(83)$ & $82.4(164)$ & $81.5(247)$ & \multirow[t]{2}{*}{.58} \\
\hline No & $20.2(21)$ & $17.6(35)$ & $18.5(56)$ & \\
\hline \multicolumn{5}{|l|}{ Eat fruits and vegetables daily } \\
\hline Yes & $39.4(41)$ & $36.4(72)$ & $37.4(113)$ & \multirow[t]{2}{*}{.60} \\
\hline No & $60.6(63)$ & $63.6(126)$ & $62.6(189)$ & \\
\hline \multicolumn{5}{|l|}{ History of high blood presure } \\
\hline No & $69.2(72)$ & $65.3(130)$ & $66.7(202)$ & \multirow[t]{2}{*}{.49} \\
\hline Yes & $30.8(32)$ & $34.7(69)$ & $33.3(101)$ & \\
\hline \multicolumn{5}{|l|}{ Previous high blood sugar } \\
\hline No & - & - & $87.1(263)$ & \multirow[t]{2}{*}{$<.001$} \\
\hline Yes & - & - & $12.9(39)$ & \\
\hline \multicolumn{5}{|l|}{ Macrosomia (females only) } \\
\hline No & $\mathrm{n} / \mathrm{a}$ & 76.4 (152) & $\mathrm{n} / \mathrm{a}$ & \multirow[t]{2}{*}{$\mathrm{n} / \mathrm{a}$} \\
\hline Yes & $\mathrm{n} / \mathrm{a}$ & $23.6(47)$ & $\mathrm{n} / \mathrm{a}$ & \\
\hline \multicolumn{5}{|l|}{ Country food } \\
\hline Yes & 56.7 (59) & $52.8(105)$ & $54.1(164)$ & \multirow[t]{2}{*}{.06} \\
\hline No & $43.3(45)$ & $47.2(94)$ & 45.9 (139) & \\
\hline \multicolumn{5}{|l|}{ Daily junk food } \\
\hline Yes & $14.4(15)$ & $7.5(15)$ & $9.9(30)$ & \multirow[t]{2}{*}{.51} \\
\hline No & $85.6(89)$ & 92.5 (184) & $90.1(273)$ & \\
\hline Total & $34.3(104)$ & 65.7 (199) & $100(303)$ & \\
\hline
\end{tabular}

Abbreviation: n/a, not applicable.

Note: “-” signifies $\mathrm{n}<5$, suppressed to protect privacy.

${ }^{a}$ Waist circumference: small, males $<94 \mathrm{~cm}$ and females $<80 \mathrm{~cm}$; medium, males $94-102 \mathrm{~cm}$ and females $80-88 \mathrm{~cm}$; large, males $>102 \mathrm{~cm}$ and females $>88 \mathrm{~cm}$. 
TABLE 3

Dysglycemia status of CANRISK Kitikmeot Region (Nunavut) study participants, Canada, 2013

\begin{tabular}{lccc}
\multicolumn{1}{c}{ Community } & $\begin{array}{c}\text { Prediabetes } \\
\%(\mathbf{n})\end{array}$ & $\begin{array}{c}\text { Diabetes }^{\mathbf{a}} \\
\%(\mathbf{n})\end{array}$ & $\begin{array}{c}\text { Dysglycemia } \\
\%(\mathbf{n})\end{array}$ \\
\hline Cambridge Bay & $22(18)$ & $9(7)$ & $31(25)$ \\
Gjoa Haven & $12(9)$ & 0 & $12(9)$ \\
Kugaaruk & $21(6)$ & 0 & $21(6)$ \\
Kugluktuk & - & - & $21(16)$ \\
Taloyoak & - & - & $26(11)$ \\
Total & $18(55)$ & $4(12)$ & $22(67)$ \\
\hline
\end{tabular}

Note: “-” signifies $n<5$, suppressed to protect privacy.

${ }^{a}$ Since participants with confirmed diabetes were excluded from the CANRISK survey, only previously undiagnosed diabetes cases were included in this column.

(giving birth to a baby weighing $4.1 \mathrm{~kg}$ [9 lbs] or more) were significant predictors of dysglycemia in the fully adjusted models. The odds of dysglycemia increased with age although not all estimates were statistically significant; the odds of dysglycemia by BMI and waist circumstance appeared to follow a U-shape. In Model 1, which included supplementary diet variables, the Hosmer-Lemeshow goodness of fit for the full model was $p=.35$, the max-rescaled pseudo-R-square was 0.23 , and area under the curve (AUC) was 0.75. For Model 2, the CANRISK model without supplementary variables, the HosmerLemeshow goodness of fit was $p=.94$, the max-rescaled pseudo-R-square was 0.22 and AUC was 0.75. The max-rescaled pseudo-R-square was marginally better for Model 1, which is to be expected given it is a model with more predictors. The Hosmer-Lemeshow goodness of fit indicated that both models fit the data well. Both models have comparable accuracy based on the AUC.

We calculated the CANRISK score for each individual. Sensitivity and specificity calculations based on the CANRISK thresholds $^{12}$ are presented in Table 5 . When we used the "high" CANRISK score of 33 or over as the classification criterion for dysglycemia, the sensitivity was $61 \%$ and the specificity was $67 \%$; however, when we used the "slightly elevated" CANRISK score of 21 or over, the sensitivity was $85 \%$ and the specificity was $31 \%$ (Table 5 ). A posthoc power calculation indicated that the study was powered at 0.84 against a null hypothesis of the dysglycemia prevalence rate of $0.15(\alpha=0.05)$.

\section{Discussion}

The prediabetes (18\% vs. $16 \%$ ) and the undiagnosed diabetics ( $4 \%$ vs. $5 \%$ ) estimates in the Kitikmeot region of Nunavut were very similar to those identified in the data collection sites in seven provinces (British Columbia, Saskatchewan, Manitoba, Ontario, New Brunswick, Nova Scotia and Prince Edward Island) in the original CANRISK study. ${ }^{12}$ The Nunavut population sampled was significantly younger on average than that obtained in other CANRISK data collection sites, which should have resulted in fewer identified cases. However, the prevalence of undiagnosed diabetes in this convenience sample also approximates the prevalence of diabetes identified in the International Polar Year Inuit Health Survey for Adults based on OGTT. ${ }^{8}$

The prevalence of dysglycemia increased exponentially with age in the current study population, with the odds doubling with every 10 years of age, whereas a more modest linear increasing trend in the OR for age $^{12}$ was noted for original CANRISK data. It is unclear whether this is a function of a relatively small sample size, or whether it reflects some underlying difference in risk by age for what was largely an Inuit population.

The association between BMI and dysglycemia in Nunavut did not show a linear increase, as was reported for the original CANRISK study; ${ }^{12}$ instead, a U-shaped relationship is suggested, though it is not statistically significant. A similar U-shaped relationship is also suggested for waist circumference, though the relationship here is also not statistically significant. These observations suggest that BMI cutoff points representing categories of increased health risk may need to be adjusted for Inuit populations. This finding is supported by a study of Inuit in Greenland, which observed the tendency for shorter legs relative to torso among the Inuit would result in a BMI overweight cut-off point of 27 instead of the WHO standard of $25 .{ }^{26}$ Similarly, a BMI of around 27 among Inuit corresponded to the same degree of dyslipidemia as observed for a BMI of 25 among non-Inuit. ${ }^{26}$

In the last few decades, traditional foods have been replaced in Indigenous communities in Canada by processed foods, which are higher in refined carbohydrates, fat, sodium and sugar. ${ }^{27,28}$ This change has had an impact on the development of diabetes and other chronic diseases..$^{27,28}$ Although not statistically significant, the results of our study suggested that frequent consumption of country food was associated with lower odds of dysglycemia, and that junk food was positively associated with dysglycemia.

The Inuit population of Nunavut is the youngest in Canada, with a median age of 23 years, compared to that of the nonIndigenous population in Canada (41 years). ${ }^{29}$ Although the CANRISK tool has been previously validated for a multi-ethnic sample, our purpose in this study was to target the Inuit population. This meant that our sample was younger than that of the previous CANRISK study. However, two-thirds of our participants were still in the group aged 40 years and over.

Our study was consistent with the previous CANRISK study when we used the "balanced" and "high" scoring categories to indicate individuals' risk of dysglycemia. ${ }^{12}$ Comparing the "high" category ( $\geq 33$ points) to the data from the sevenprovince CANRISK, we found a sensitivity of $61 \%$ versus $66 \%$; specificity of $67 \%$ versus $70 \%$; positive predictive value of $34 \%$ versus $36 \%$ and a total accuracy rate of $65 \%$ versus $64 \%$. It is important to note that there is no ideal or recommended sensitivity and specificity for a tool to identify individuals with a high risk of dysglycemia. Although it is desirable to have a screening tool that is both highly sensitive and highly specific, this is 
TABLE 4

Logistic regression models using CANRISK, Kitikmeot Region (Nunavut), Canada, 2013

\begin{tabular}{|c|c|c|c|c|}
\hline \multirow[b]{2}{*}{ Risk factor } & \multicolumn{2}{|c|}{$\begin{array}{l}\text { Model 1. CANRISK model with supplementary diet variables } \\
\qquad \mathrm{N}=303\end{array}$} & \multicolumn{2}{|c|}{$\begin{array}{l}\text { Model 2. CANRISK model } \\
\qquad \mathrm{N}=303\end{array}$} \\
\hline & Adjusted OR & $95 \% \mathrm{Cl}$ & Adjusted OR & $95 \% \mathrm{Cl}$ \\
\hline$<44$ & Ref & & Ref & \\
\hline $45-54$ & 1.46 & $0.63-3.35$ & 1.44 & $0.63-3.30$ \\
\hline $55-64$ & $4.12^{\mathrm{a}}$ & $1.73-9.82$ & $3.79^{\mathrm{a}}$ & $1.62-8.90$ \\
\hline$<25$ & Ref & & Ref & \\
\hline 25 to $<30$ & 0.68 & $0.17-2.64$ & 0.72 & $0.19-2.80$ \\
\hline 30 to $<35$ & 0.68 & $0.15-3.05$ & 0.71 & $0.16-3.16$ \\
\hline $35+$ & 1.33 & $0.30-5.81$ & 1.44 & $0.33-6.27$ \\
\hline \multicolumn{5}{|l|}{ Waist circumference ${ }^{b}$} \\
\hline Some college or university & Ref & & Ref & \\
\hline High school & 1.09 & $0.29-4.01$ & 1.00 & $0.27-3.70$ \\
\hline Less than high school & 0.70 & $0.30-1.62$ & 0.70 & $0.31-1.59$ \\
\hline \multicolumn{5}{|l|}{30 minutes daily physical activity } \\
\hline Yes & Ref & & Ref & \\
\hline No & 1.33 & $0.62-2.85$ & 1.35 & $0.63-2.91$ \\
\hline \multicolumn{5}{|l|}{ Eat fruits and vegetables daily } \\
\hline Yes & Ref & & Ref & \\
\hline No & 0.97 & $0.47-1.99$ & 1.02 & $0.50-2.07$ \\
\hline \multicolumn{5}{|l|}{ History of high blood pressure } \\
\hline Male & 1.45 & $0.69-3.06$ & 1.45 & $0.69-3.07$ \\
\hline \multicolumn{5}{|l|}{ Previous high blood sugar } \\
\hline No & Ref & & Ref & \\
\hline Yes & 1.47 & $0.59-3.70$ & 1.35 & $0.55-3.32$ \\
\hline \multicolumn{5}{|l|}{ Macrosomia (females only) ${ }^{c}$} \\
\hline No & Ref & & Ref & \\
\hline Yes & $2.65^{\mathrm{a}}$ & $1.12-6.25$ & $2.63^{\mathrm{a}}$ & $1.13-6.09$ \\
\hline \multicolumn{5}{|l|}{ Eat country food weekly } \\
\hline No & Ref & & & \\
\hline Yes & 0.73 & $0.40-1.37$ & & \\
\hline \multicolumn{5}{|l|}{ Eat/drink junk food daily } \\
\hline No & Ref & & & \\
\hline Yes & 1.53 & $0.53-4.47$ & & \\
\hline \multicolumn{5}{|c|}{ Model fit statistics and ROC } \\
\hline Hosmer-Lemeshow goodness of fit $(p)$ & 0.35 & & 0.94 & \\
\hline Max-rescaled pseudo-R-square & 0.23 & & 0.22 & \\
\hline AUC & 0.75 & & 0.75 & \\
\hline
\end{tabular}

Abbreviations: AUC, area under the curve; $\mathrm{Cl}$, confidence interval; OR, odds ratio; Ref, reference group; ROC, receiver operating curve.

Note: Shaded cells signify variables not included in the model.

${ }^{a}$ Indicates significance at $p<.05$.

${ }^{\mathrm{b}}$ Waist circumference: small, males $<94 \mathrm{~cm}$ and females $<80 \mathrm{~cm}$; medium, males $94-102 \mathrm{~cm}$ and females $80-88 \mathrm{~cm}$; large, males $>102 \mathrm{~cm}$ and females $>88 \mathrm{~cm}$.

' The macrosomia estimate was calculated in the same model as the other parameters. Males were included as a third category, separate from the reference group. 
TABLE 5

Validation of CANRISK tool and score thresholds in Kitikmeot Region (Nunavut), Canada, 2013

\begin{tabular}{|c|c|c|c|c|}
\hline \multirow{2}{*}{ Validation analysis } & \multicolumn{4}{|c|}{ CANRISK score } \\
\hline & Slightly elevated $\geq 21$ & Moderate $\geq 29$ & Balanced $^{\mathrm{a}} \geq 32$ & High $\geq 33$ \\
\hline Sensitivity & $85.1 \%$ & $65.7 \%$ & $61.2 \%$ & $61.2 \%$ \\
\hline Positive predictive value & $26.0 \%$ & $29.5 \%$ & $33.6 \%$ & $34.2 \%$ \\
\hline Total accuracy rate & $43.2 \%$ & $57.8 \%$ & $64.7 \%$ & $65.3 \%$ \\
\hline
\end{tabular}

${ }^{a}$ A balanced score of CANRISK is an optimal score that attempts to balance the sensitivity and specificity of the test.

usually not possible, as increasing one reduces the other. The chosen balance is a compromise that weights the relative importance of minimizing false positives and false negatives. What we have done here is to report and compare our sensitivity and specificity rates to what exists in the literature for different screening tools, or for the same tool in a different population. Comparing our rates of sensitivity and specificity to those of existing biochemical tests $^{30}$ can help to determine how useful CANRISK could be as a risk-screening tool. In general, questionnaire screening tools have lower sensitivity and specificity than biochemical tests but are usually useful for educating in particular people at high risk of developing type 2 diabetes, or in situations where the advantages of ease and cost associated with questionnaires compared to biochemical tests outweigh the loss of sensitivity and specificity.

The OGTT provides a sensitivity of $90 \%$ to $93 \%$, with a specificity of $100 \%$ for identifying individuals with diabetes, and is therefore the gold standard test. ${ }^{31}$ The FPG test $(7.0 \mathrm{mmol} / \mathrm{L}$ or higher) yields a sensitivity of $40 \%$ to $59 \%$ with a specificity of $96 \%$ to $99 \% .{ }^{31}$ The FINDRISC, widely used in European populations, which was used as a model in the development of the CANRISK, is the mostresearched diabetes screening tool. ${ }^{32} \mathrm{~A}$ FINDRISC score of greater than or equal to 12 yields a sensitivity of $78 \%$ and a specificity of $62 \%$; a cut-off point of FINDRISC greater than or equal to 10 results in a sensitivity of $84 \%$ and a specificity of $61 \%$. The original CANRISK tool had a sensitivity of $70 \%$, and a specificity of $67 \%$ using a cut-off point of 32 , in a larger, multi-ethnic sample of Canadians. ${ }^{12}$ It has been used primarily as an educational tool and its potential role in clinical screening has not been assessed. Given all of this information, one can see that the predictive ability of the CANRISK tool in the Nunavut population is acceptable compared to what else is available (apart from the OGTT), with the additional advantage that it is a simple, easy-to-use, self-administered questionnaire.

Like the previous analysis of CANRISK that was based on provincial populations, we opted to use FPG and/or OGTT as the basis for determining dysglycemic status. The choice of which test to use is problematic in that the tests are by no means entirely interchangeable, and groups identified by each test do not always overlap. For example, the analysis of the CANRISK data for the seven provinces noted that FPG would have failed to detect $52 \%$ of the diabetes cases and $59 \%$ of the prediabetes cases identified by the 2-hour oral glucose challenge test. ${ }^{12}$ However, we used both the FPG and OGTT, and given the high sensitivity of OGTT, it is unlikely that we have failed to detect true cases. The choice to use FPG and/or OGTT in the current analysis was in part to provide comparability to the data generated by the earlier seven-province CANRISK analysis. ${ }^{12,13}$ Also, OGTT is still considered by most clinicians to be the gold standard for the diagnosis of diabetes.

\section{Strengths and limitations}

Given lifestyle changes in the last few decades, more evidence is needed regarding diabetes prevention and early detection among Inuit populations. Our study provides emerging evidence in a timely manner as to how the CANRISK tool may be applied to the Inuit population.

Our study had several limitations. Females were overrepresented in our sample, although the age distribution was comparable to that of the corresponding 2011 census. ${ }^{33}$ The effect of the oversampling of females is important only if there are significant interactions between the risk factors in the model and dysglycemia. The proportions of people in our sample who had less than a high school education $(69 \%)$ or who were Inuit $(84 \%)$ were also comparable to census data $(62 \%$ and $90 \%{ }^{33}$ ), suggesting that although we used a convenience sample, with the exception of oversampling females, our study appeared to have been broadly representative of the study population.

This study relied on a convenience sample of volunteers, and it was not possible to fully investigate the difference between volunteers and the remainder of the population. Therefore, the rates of undiagnosed diabetes and prediabetes among volunteers may not be representative of the region studied or the wider population of Nunavut. Additionally, because we excluded participants with diagnosed diabetes, we are only able to present rates of prediabetes and undiagnosed diabetes. The total burden of dysglycemia in these communities cannot be estimated, due to low participation rates and our inability to determine systematically whether participants differed from nonparticipants. Perhaps the biggest limitation of the study was its small sample size and the resulting lack of precision in our odds ratios.

As with other diabetes screening tools such as AUSDRISK ${ }^{19}$ and FINDRISC, ${ }^{11}$ CANRISK used a single predictive model for all included ages. Although CANRISK performed reasonably well at predicting dysglycemia within our population, given our small sample size, we were not able to examine reliably how well CANRISK performed for those aged under 40 years. Although the CANRISK tool was developed from a sample that included individuals aged 18 years and older, the CANRISK tool is currently recommended for those 
aged 40 years and older. This limitation is particularly significant for Inuit populations, given their much younger age distribution. Further research is needed to address how well diabetes-risk screening tools perform for younger populations.

\section{Conclusion}

A logistic regression model had acceptable model fit when we used CANRISK variables to predict dysglycemia. Further, categories of risk based on scores from the original CANRISK tool achieved a similar accuracy in detecting true dysglycemia in this mainly Inuit sample as in a multiethnic sample in Canada. We found the CANRISK tool to be adaptable to the Kitikmeot region of Nunavut, and therefore the tool may be utilized in a similar way in Nunavut region as well. Using the CANRISK tool to identify the levels of dysglycemia risk, individuals, communities and local health authorities can take appropriate measures to reduce the burden of dysglycemia in the Inuit population.

\section{Acknowledgements}

We gratefully acknowledge the Nunavut Department of Health, Kitikmeot Inuit Association, and five communities in the Kitikmeot region of Nunavut (Cambridge Bay, Gjoa Haven, Kugaaruk, Kugluktuk and Taloyoak) for their support.

\section{Conflicts of interest}

The authors have no conflicts of interest to disclose.

\section{Authors' contributions}

YJ, YM and HM contributed substantially to the study design and drafted the paper. YM, SRVK and YJ analysed the data. MS and RC developed tools and completed data acquisition. HO, GA, MG, HM, YM, SRVK and YJ reviewed and revised the paper. All authors read and gave final approval of this version to be published and agreed to be guarantors of the work.

\section{References}

1. Canadian Diabetes Association, Diabetes Quebec. Diabetes: Canada at the tipping point-charting a new path [Internet]. Canada: Canadian Diabetes Association; 2011. Available from: http://www.diabetes.ca/CDA /media/documents/publications -and-newsletters/advocacy-reports /canada-at-the-tipping-point-english .pdf
2. Government of Canada. Chronic Disease and Injury Indicator Framework: quick stats [Internet]. Ottawa $(\mathrm{ON})$ : Public Health Agency of Canada; 2015 [updated 2015 Dec 8; cited 2016 Jun 28]. Available from: http:// infobase.phac-aspc.gc.ca/cdiif/

3. Public Health Agency of Canada. Diabetes in Canada: facts and figures from a public health perspective. Ottawa (ON): Public Health Agency of Canada; 2011 [Catalogue No.: HP35 $-25 / 2011 E]$.

4. International Diabetes Federation. Risk factors [Internet]. Brussels: International Diabetes Federation. 2015 [cited 2016 Apr 18]. Available from: http://www.idf.org/about-diabetes /risk-factors

5. American Diabetes Association. Age, race, gender \& family history [Internet]. Arlington (VA): American Diabetes Association; 2014 [updated 2014 Feb 12; cited 2016 Apr 20]. Available from: http://www.diabetes.org/are - you - at - risk / lower-your-risk /nonmodifiables.html

6. Shah A, Kanaya AM. Diabetes and associated complications in the South Asian population. Curr Cardiol Rep. 2014;16(5):476.

7. Young TK, Schraer CD, Shubnikoff EV, Szathmary EJ, Nikitin YP. Prevalence of diagnosed diabetes in circumpolar indigenous populations. Int J Epidemiol. 1992;21(4):730-6.

8. Egeland GM, Cao Z, Young TK. Hypertriglyceridemic-waist phenotype and glucose intolerance among Canadian Inuit: the International Polar Year Inuit Health Survey for Adults 2007-2008. CMAJ. 2011;183(9): E553-E558.

9. Statistics Canada. CANSIM database: Table 105-0507. Measured adult body mass index (BMI), by age group and sex, household population aged 18 and over excluding pregnant females, Canada (excluding territories). [Internet]. Ottawa (ON): Statistics Canada; 2009 Jun 24 [cited 2015 Jun 9]. Available from: http://www5 .statcan.gc.ca/cansim/a26?lang = eng \&id $=1050507$
10. Canadian Diabetes Association Clinical Practice Guidelines Expert Committee, Ekoe JM, Punthakee Z, Ransom T, Prebtani AP, Goldenberg R. Screening for type 1 and type 2 diabetes. Can J Diabetes. 2013;37 Suppl 1:S12-S15.

11. Lindstrom J, Tuomilehto J. The diabetes risk score: a practical tool to predict type 2 diabetes risk. Diabetes Care. 2003;26(3):725-31.

12. Robinson CA, Agarwal G, Nerenberg $\mathrm{K}$. Validating the CANRISK prognostic model for assessing diabetes risk in Canada's multi-ethnic population. Chronic Dis Inj Can. 2011;32(1): 19-31.

13. Kaczorowski J, Robinson C, Nerenberg K. Development of the CANRISK questionnaire to screen for prediabetes and undiagnosed type 2 diabetes. Can J Diabetes. 2009;33(4): 381-5.

14. Altman DG, Vergouwe Y, Royston P, Moons KG. Prognosis and prognostic research: validating a prognostic model. BMJ. 2009;338:b605.

15. Altman DG, Royston P. What do we mean by validating a prognostic model? Stat Med. 2000;19(4):453-73.

16. CANRISK diabetes questionnaire [Internet]. Fredericton (NB): New Brunswick Health; 2014 [updated 2014 Sep 10; cited 2015 Jun 9]. Available from: http://www2.gnb.ca /content/gnb/en/departments/health / p a t i e n t i n f or mat i o n / P r i m a r y H e a $1 \mathrm{th} \mathrm{C}$ a r e / A -Comprehensive-Diabetes-Strategy -for-New-Brunswickers-2011-2015 /CANRISK_Diabetes_Questionnaire .html

17. Are you at risk? [Internet]. Toronto (ON): Shoppers Drug Mart; 2015 [updated 2015 Mar 31; cited 2015 Jun 9]. Available from: http://canrisk .shoppersdrugmart.ca/

18. Take the Test [Internet]. Canada: Canadian Diabetes Association; 2014 [updated 2014 Nov 5; cited 2015 Jun 9]. Available from: www.diabetes.ca /take-the-test/

19. Chen L, Magliano DJ, Balkau B, et al. AUSDRISK: an Australian Type 2 Diabetes Risk Assessment Tool based on demographic, lifestyle and simple anthropometric measures. Med J Aust 2010;192(4):197-202. 
20. Diabetes UK. Diabetes Risk Score Assessment Tool [Internet]. London: Diabetes UK; 2015 [cited 2015 Jul 9]. Available from: https://www.diabetes .org.uk/Professionals/Diabetes-Risk -Score-assessment-tool/

21. American Diabetes Association. Type 2 Diabetes Risk Test [Internet]. Arlington (VA): American Diabetes Association; 2015 [cited 2015 Jun 9]. Available from: http://www.diabetes. org/are-you-at-risk/diabetes-risk -test/

22. Canadian Institutes of Health Research (CIHR), Natural Sciences and Engineering Research Council of Canada (NSERCC), Social Sciences and Humanities Research Council of Canada (SSHRCC). Chapter 9: Research involving the First Nations, Inuit and Métis peoples of Canada. In: Tri-Council policy statement: ethical conduct for research involving humans. Ottawa (ON): CIHR, NSERCC, SSHRCC [Catalogue No.: MRd21-18/2010E -PDF] 2010;105-34.

23. World Health Organization, International Diabetes Federation. Definition and diagnosis of diabetes mellitus and intermediate hyperglycemia: report of a WHO/IDF consultation. Geneva (CH): World Health Organization; 2006.

24. World Health Organization. Obesity: preventing and managing the global epidemic. Report of a WHO consultation. Geneva $(\mathrm{CH})$ : World Health Organization; 2000 [Technical Report Series 894].

25. Canadian Diabetes Association Clinical Practice Guidelines Expert Committee, Wharton S, Sharma AM, Lau DC. Weight management in diabetes. Can J Diabetes. 2013;37 Suppl 1:S82-S86.

26. Andersen S, Fleischer Rex K, Noahsen P, Sorensen HC, Mulvad G, Laurberg P. Raised BMI cut-off for overweight in Greenland Inuit-a review. Int J Circumpolar Health. 2013;72:21086. doi: 10.3402/ijch.v72i0.21086.

27. Sharma S, Cao X, Roache C, Buchan A, Reid R, Gittelsohn J. Assessing dietary intake in a population undergoing a rapid transition in diet and lifestyle: the Arctic Inuit in Nunavut, Canada. Br J Nutr. 2010;103(5):749-59.
28. National Collaborating Centre for Aboriginal Health. Nutrition fact sheet [Internet]. Prince George (BC): National Collaborating Centre for Aboriginal Health; 2013 [cited 2015 Jun 9]. Available from: http://www.nccah -ccnsa.ca/Publications/Lists /Publications / Attachments / 71 /Nutrition.pdf

29. Statistics Canada. Aboriginal peoples in Canada: First Nations people, Métis and Inuit: National Household Survey 2011 (Table 4) [Internet]. Ottawa (ON): Statistics Canada; 2013 [updated 2015 Dec 23; cited 2016 Jul 19]. Available from: http://www 12 .statcan.gc.ca/nhs-enm/2011/as-sa /99-011-x/99-011-x2011001-eng.cfm

30. Canadian Task Force on Preventive Health Care, Pottie K, Jaramillo A, et al. Recommendations on screening for type 2 diabetes in adults. CMAJ. 2012;184(15):1687-96.

31. Engelgau MM, Narayan KM, Herman WH. Screening for type 2 diabetes. Diabetes Care. 2000;23(10):1563-80.

32. Echouffo-Tcheugui JB, Ali MK, Griffin SJ, Narayan KM. Screening for type 2 diabetes and dysglycemia. Epidemiol Rev. 2011;33(1):63-87.

33. Statistics Canada. Kitikmeot, REG, Nunavut (Code 6208) (table). National Household Survey (NHS) profile. 2011 National Household Survey [Internet]. Ottawa (ON): Statistics Canada; 2013 Sep 11 [cited 2015 Jun 9]. Available from: http://www12.statcan.gc.ca/ nhs-enm/2011/dp-pd/prof/index .cfm?Lang $=\mathrm{E}$ 